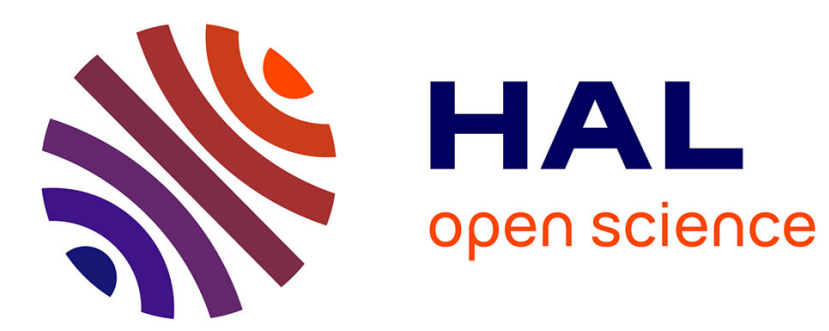

\title{
LE TRYPTOPHANE ET LA LYSINE DANS LE LAIT DE BREBIS
}

\author{
Pr Dr L.-M. Buruiana, Dr C. Stoian, El. Hadarag, A. Dema
}

\section{To cite this version:}

Pr Dr L.-M. Buruiana, Dr C. Stoian, El. Hadarag, A. Dema. LE TRYPTOPHANE ET LA LYSINE

DANS LE LAIT DE BREBIS. Le Lait, 1960, 40 (393_394), pp.129-134. hal-00928263

\section{HAL Id: hal-00928263 \\ https://hal.science/hal-00928263}

Submitted on 1 Jan 1960

HAL is a multi-disciplinary open access archive for the deposit and dissemination of scientific research documents, whether they are published or not. The documents may come from teaching and research institutions in France or abroad, or from public or private research centers.
L'archive ouverte pluridisciplinaire HAL, est destinée au dépôt et à la diffusion de documents scientifiques de niveau recherche, publiés ou non, émanant des établissements d'enseignement et de recherche français ou étrangers, des laboratoires publics ou privés. 


\title{
LE LAIT
}

REVUE GENERAE DES QUESTIONS LAITIERES

SOMMAIRE

\section{Mémoires originaux :}

L. M. Buruiana, C. Stotan, El. Hadarag ot A. Dema. - Le tryptophane et la lysine dans le lait de brebis

J. PIEn. - La graduation des butyromètres à lait . .

P. Dopter, - Essais de dosage d'antibiotiques dans le lait . . . . . . . .

L. Serres, S, Amariglio, L. Bernard, D. Robinet. Contribution à l'étude des méthodes de recherche des neutralisants dans les poudres de lait écrémé (à suivre)

Revue :

G. Génin. - Le lait dans le monde... . . . . .

Bibliographie analytique :

10 Les livres

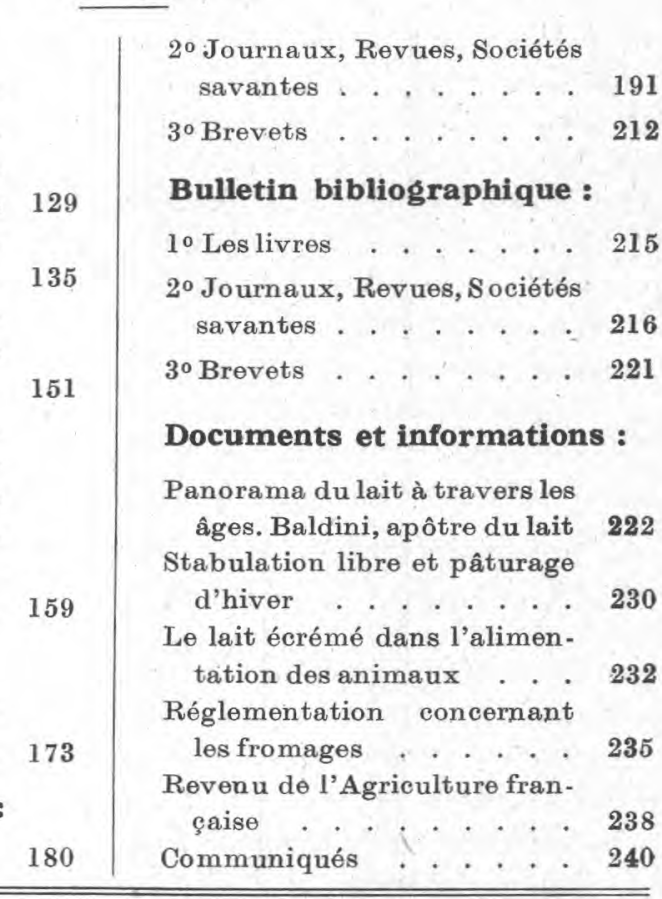

\section{MÉMOIRES OṘGINAUX (1)}

\section{LE TRYPTOPHANE ET LA LYSINE DANS LE LAIT DE BREBIS}

\author{
par
}

Pr $^{\mathrm{T}} \mathrm{D}^{\mathrm{r}}$ L.-M. BURUIANA, $\mathrm{D}^{\mathrm{r}} \mathrm{C}$. STOIAN, EL. HADARAG et A. DEMA

Laboratoire de Biochimie, Faculté de Médecine Vétérinaire Bucarest (Roumanie)

Les sources d'amino-acides essentiels présentent un intérêt de premier ordre pour l'alimentation des hommes et des animaux. La valeur biologique des protéines peut être appréciée avec succès

(1) Reproduction interdite sans indication de source. 
d'après leur teneur seulement en quelques amino-acides [6], surtout le tryptophane et la lysine.

Quoique dans les derniers temps la composition en aminoacides des diverses protéines ait fait l'objet de nombreuses recherches, il existe des indications très réduites [7] sur le contenu du lait de brebis en amino-acides essentiels.

La République populaire roumaine est un pays où le lait de brebis occupe une place importante dans la production laitière et dans l'industrie fromagère. La plus grande quantité de fromage produite dans le pays provient du lait de brebis, et cet aliment, particulièrement apprécié, constitue une importante source de matière protéique dans l'alimentation de la population.

Nous exposons, dans le présent travail, une partie des résultats obtenus à l'occasion des recherches entreprises pour déterminer la valeur alimentaire des protéines du lait de brebis et les modifications subies par celle-ci pendant les diverses manipulations.

Nos premiers résultats se réfèrent au contenu en tryptophane et en lysine.

\section{Le tryptophane du lait de brebis}

Le contenu en tryptophane des protéines et surtout de la caséine de lait de vache est une des questions les plus discutées dans l'histoire de cet amino-acide. Depuis Hopkins (1901) qui a réussi à isoler, de la caséine, une quantité de 1 gr. $5 \%$ de tryptophane, nombre de chercheurs ont vérifié, à l'aide de différentes méthodes, ce premier chiffre. Les résultats obtenus ont été très disparates (voir surtout l'introduction du travail de Sullivan et Hess [10]) Ils oscillent entre 0,5 et $2,4 \%$.

Block et Bolling [2] sont d'avis que cette non concordance doit être attribuée surtout aux carences des méthodes employées pour le dosage.

Nous avons utilisé, pour le dosage du tryptophane, la méthode de Bates [1], en tenant compte des observations et des modifications proposées par Sullivan et Hess (loc. cit.). Les vérifications faites à l'oceasion d'un travail antérieur [3] nous ont convaincu de l'exactitude de cette technique. Nous sommes d'avis que les résultats si différents, obtenus par les divers chercheurs, sont dus, non seulement à la carence des méthodes, mais aussi à d'autres causes dont nous citons les suivantes :

1. Le contenu en tryptophane des protéines du lait n'est pas constant, fait remarqué aussi par BLOCK et BoLLING;

2. La séparation de la caséine à l'aide des différents réactifs peut modifier son contenu en tryptophane, fait observé aussi par Sullivan et Hess (loc. cit.); 
3. Le dosage du tryptophane doit être fait sur l'hydrolysat et non sur la protéine native, car l'intensité de la coloration dépend aussi du poids moléculaire du complexe colorant;

4. La réaction au $p$-diméthylaminobenzaldéhyde n'est pas spécifique. Il est fort probable que dans la composition des protéines du lait, il existe aussi des dérivés qui s'apparentent au tryptophane et qui en dérivent.

En tenant compte de ces possibilités, nous avons déterminé le tryptophane dans le lait de brebis des plus importantes races du pays, élevées dans la plaine du Danube et en Dobroudja. Les analyses ont été exécutées pendant la saison de production laitière maximum (mai, juin, juillet) période pendant laquelle les animaux ont été alimenté au pâturage.

Les déterminations ont été faites après hydrolyse en milieu alcalin $(\mathrm{NaOH}, 5 \mathrm{~N})$ pendant deux heures à 2 atmosphères. Pour l'hydrolyse, on a utilisé le lait frais, de grand mélange, ou les protéines précipitées à l'aide de l'acide trichloracétique. Le différences étaient petites, car le tryptophane libre et l'indican du lait sont en petite quantité.

\section{La lysine du lait de brebis}

Le rôle de la lysine dans le bilan azoté de l'organisme ne doit plus être souligné. C'est pour cela que, parmi les méthodes récentes employées pour apprécier la valeur nutritive des protéines, le dosage de la lysine constitue une technique de choix. Le bilan de la lysine pendant les traitements thermiques subis par les divers aliments procure aussi des indications sur la dégradation des protéines [4].

Les protéines du lait constituent la source la plus riche en lysine. Le dosage de la lysine présente de sérieuses difficultés. C'est pour cela que presque toutes les méthodes, depuis Kossex, recourent premièrement à sa séparation des autres amino-acides de l'hydrolysat protéique. Dans le eas du lait, la difficulté est accrue par la présence de glucides qui contribuent à sa transformation, comme l'ont prouvé Sentheshanmuganathan et Hoover [9].

Nous avons done recouru à la méthode préconisée par CARpenter et Ellinger [5], qui est basée sur la réaction du fluorodinitrobenzène (SANGER) avec les groupements libres $\varepsilon-\mathrm{NH}_{2}$ de la lysine. La technique de travail fut celle de Scober et Prinz [8], légèrement modifiée par nous. Dans le cas des protéines du lait, cette méthode détermine le contenu total en lysine, car elles contiennent tous les groupements $\varepsilon-\mathrm{NH}_{2}$ de la lysine des chaînes polypeptidiques libres.

Dans le tableau I, sont enregistrés les résultats obtenus. 


\section{TABL EAU I}

\begin{tabular}{|c|c|c|c|c|c|c|c|}
\hline \multirow{3}{*}{$\begin{array}{c}\text { No } \\
\text { échant. }\end{array}$} & \multirow{2}{*}{\multicolumn{3}{|c|}{$\begin{array}{l}\text { Matières protéiques pour } \\
100 \mathrm{ml} \text {. de lait de brebis }\end{array}$}} & \multicolumn{4}{|c|}{ Contenu en grammes } \\
\hline & & & & \multicolumn{2}{|c|}{ Tryptophane } & \multicolumn{2}{|c|}{ Lysin $\theta$} \\
\hline & $\begin{array}{l}\text { Protéines } \\
\text { totales gr. }\end{array}$ & $\begin{array}{l}\text { Caséine } \\
\text { gr. }\end{array}$ & r & $\begin{array}{l}\text { pour } 100 \\
\text { ml. lait }\end{array}$ & $\begin{array}{l}\text { pour } 100 \mathrm{gr} \text {. } \\
\text { protéines }\end{array}$ & $\begin{array}{c}\text { pour } 100 \\
\text { ml. lait }\end{array}$ & $\begin{array}{c}\text { pour } 100 \mathrm{gr} . \\
\text { protéines }\end{array}$ \\
\hline $1 \ldots$ & 4,75 & - & & 0,177 & 3,74 & 0,644 & 13,50 \\
\hline $2 \ldots$ & 4,75 & - & & 0,200 & 4,21 & 0,664 & 13,50 \\
\hline $3 \ldots$ & 5,07 & 4,35 & & 0,171 & 3,37 & 0,697 & 13,70 \\
\hline $4 \ldots$ & 5,12 & 4,35 & & 0,160 & 3,12 & 0,731 & 14,08 \\
\hline $5 \ldots$ & 4,62 & 3,98 & & 0,200 & 4,32 & 0,642 & 13,91 \\
\hline $6 \ldots$ & 4,57 & 4,01 & & 0,150 & 3,28 & 0,769 & 16,83 \\
\hline $7 \ldots$ & 6,62 & 5,53 & & 0,150 & 2,28 & 0,663 & 10,18 \\
\hline $8 \ldots$ & 5,07 & 4,61 & & 0,177 & 3,51 & 0,759 & 14,97 \\
\hline $9 \ldots$ & 5,62 & 5,06 & & 0,160 & 2,84 & 0,836 & 14,86 \\
\hline $10 \ldots$ & 5,20 & 4,42 & & 0,150 & 2,88 & 0,624 & 12,00 \\
\hline $11 \ldots$ & 4,95 & 4,35 & & 0,142 & 2,87 & 0,639 & 12,91 \\
\hline $12 \ldots$ & 4,35 & 3,85 & & 0,142 & 3,49 & 0,622 & 14,30 \\
\hline $13 \ldots$ & 4,57 & 4,00 & & 0,142 & 3,10 & 0,518 & 11,34 \\
\hline $14 \ldots \ldots$ & 6,35 & 4,84 & & 0,160 & 2,52 & 0,449 & 7,08 \\
\hline $15 \ldots$ & 6,00 & 4,44 & & 0,166 & 2,76 & 0,434 & 7,23 \\
\hline $16 \ldots$ & 6,00 & 4,54 & & 0,160 & 2,66 & 0,613 & 10,23 \\
\hline $17 \ldots$ & 6,00 & 4,84 & & 0,160 & 2,66 & 0,530 & 8,83 \\
\hline $18 \ldots$ & 6,00 & 4,95 & & 0,160 & 2,66 & 0,612 & 10,20 \\
\hline $19 \ldots$ & 7,00 & 4,95 & & 0,141 & 2,01 & 0,540 & 7,71 \\
\hline $20 \ldots$ & 6,45 & 4,95 & & 0,142 & 2,20 & 0,578 & 8,96 \\
\hline $21 \ldots$ & 5,50 & 4,50 & & 0,160 & 2,90 & 0,622 & 11,30 \\
\hline $22 \ldots$ & 5,70 & 4,50 & & 0,200 & 3,50 & 0,408 & 7,15 \\
\hline $23 \ldots \ldots$ & 5,52 & 5,00 & & 0,142 & 2,57 & 0,615 & 11,14 \\
\hline $24 \ldots \ldots$ & 5,00 & 4,80 & & 0,142 & 2,80 & 0,724 & 14,29 \\
\hline $25 \ldots \ldots$ & 5,52 & 5,40 & & 0,160 & 2,90 & 0,786 & 14,24 \\
\hline $26 \ldots$ & 5,50 & 5,40 & & 0,160 & 2,90 & 0,464 & 8,43 \\
\hline $27 \ldots$ & 5,55 & 5,07 & & 0,160 & 2,88 & 0,316 & 5,70 \\
\hline $28 \ldots \ldots$ & 5,87 & 5,50 & & 0,160 & 2,72 & 0,309 & 5,27 \\
\hline $29 \ldots$ & 5,75 & 5,20 & & 0,160 & 2,88 & 0,316 & 9,02 \\
\hline $30 \ldots$ & 5,92 & 5,12 & & 0,160 & 2,70 & 0,525 & 8,87 \\
\hline $31 \ldots$ & 6,03 & 5,50 & & 0,142 & 2,30 & 0,527 & 8,74 \\
\hline $32 \ldots$ & 5,41 & 5,03 & & 0,166 & 3,06 & 0,486 & 9,00 \\
\hline $33 \ldots$ & 5,56 & 5,17 & & 0,160 & 2,87 & 0,472 & 8,49 \\
\hline $34 \ldots \ldots$ & 5,57 & 5,40 & & 0,187 & 3,34 & 0,531 & 9,57 \\
\hline $35 \ldots$ & 5,53 & 5,40 & & 0,187 & 3,34 & 0,592 & 10,62 \\
\hline
\end{tabular}

(1) Les échantillons ont été pris à partir du lait de grand mélange de troupeaux de brebis laitières, de différentes races, entre le 7 mai et le 28 juillet 1958. 
Pour avoir une idée sur la quantité de tryptophane et de lysine du lait qui passe dans le fromage, nous avons déterminé ces aminoacides, successivement, dans : le lait (avant la mise en présure), le fromage frais, le fromage après court salage, et le sérum labique. Ces expériences ont été faites sur deux lots de lait obtenus séparément, par la traite du matin et la traite du soir, de 1.400 brebis laitières de la race Spanka.

Les résultats obtenus dans ces deux cas, bien typiques, sont indiqués dans le tableau II.

TABLEAU II

\begin{tabular}{|c|c|c|c|c|}
\hline \multirow[b]{2}{*}{$\begin{array}{c}\text { Acide aminé } \\
\text { étudié }\end{array}$} & \multicolumn{4}{|c|}{ Quantité d'acide-aminé, pour $100 \mathrm{gr}$. de matière protéique, dans } \\
\hline & $\begin{array}{l}\text { Io lait } \\
\text { frais }\end{array}$ & $\begin{array}{l}\text { le fromage } \\
\text { frais }\end{array}$ & $\begin{array}{l}\text { le même fromage } \\
\text { après } 24 \mathrm{~h} \text {. de } \\
\text { salage (en saumure) }\end{array}$ & $\begin{array}{l}\text { les protéines } \\
\text { du sérum } \\
\text { labique }\end{array}$ \\
\hline \multirow{4}{*}{$\begin{array}{l}\text { Tryptophane . } \\
\text { Lysine ...... }\end{array}$} & & Lait $n^{\circ} 1$ & & \\
\hline & 3,06 & 2,53 & 2,93 & 5,09 \\
\hline & 9,00 & 7,34 & 6,95 & 19,15 \\
\hline & & Lait $n^{\circ} 2$ & $\checkmark$ & \\
\hline \multirow{2}{*}{$\begin{array}{l}\text { Tryptophane. } \\
\text { Lysine ..... }\end{array}$} & 2,30 & 2,90 & 2,27 & 4,95 \\
\hline & 8,74 & 9,48 & 8,01 & 15,20 \\
\hline
\end{tabular}

On remarque que les protéines du sérum contiennent plus de tryptophane et de lysine que le fromage frais et que, même après un court salage, le contenu de celui-ci en lysine décroît. Toutefois, la majorité des deux amino-acides du lait se retrouve dans le fromage.

\section{Conclusions}

1. Le contenu du lait de brebis en tryptophane oscille entre 0 gr. 141 et 0 gr. 200 pour 100 millilitres de lait, ou entre 2 gr. 01 et 4,32 grammes $\%$, rapporté à la matière protéique.

2. Le contenu du lait en lysine oscille entre $0 \mathrm{gr} .309$ et $0 \mathrm{gr}, 836$ pour 100 millilitres de lait, ou entre $5 \mathrm{gr} .27$ et $16 \mathrm{gr} .83 \%$ rapporté à la matière protéique.

3. On remarque la tendance d'abaissement du contenu des protéines en ces amino-acides, vers la fin de la période étudiée. Le fait peut être attribué, soit à l'augmentation du rapport, caséineprotéine, avec l'avancement de la période de lactation, soit au déclin de la qualité du pâturage pendant la saison chaude. 
4. En général, le lait de brebis constitue une source importante de tryptophane et de lysine, amino-acides qui, dans leur grande majorité, passent dans le fromage.

\section{Summary}

The amount of tryptophane contained in sheep's milk varies between 0,141 and 0,200 grams, calculated on one hundred $\mathrm{ml}$ of milk, or between 2,01 and 4,32 grams, calculated on one hundred $\mathrm{ml}$ of protein matter.

The amount of lysin contained in sheep's milk varies between 0,309 and 0,836 per hundred $\mathrm{ml}$ of milk, or between 5,27 and 16,83 grams per hundred $\mathrm{ml}$ of protein matter.

Sheep's milk is an important source of these amino-acids which, in large quantities, are passed into cheese.

\section{BIBLIOGRAPHIE}

[1] R. W. A. Bates. Rapid Methode for Quantitative Determination of Tryptophan. J. Biol. Chem., 1937, 119, vir.

[2] R. J. Block et D. Bolling. The amino acid Composition of Proteins and Foods. Charles Thomas Pub. Springfield, Ed. H, 1951.

[3] L. M. Buruiana, El. Hadarag et M. Suteanu. Continutul în tirozinà si triptofan al proteinelor serice la cîteva specii de animale. Studii si Cercetari de Chimie. Academia R. P. R., 1957, Anul V, Nr 3, 457.

[4] K. I. Carpenter. The nutritive value of proteins. Chemical Methods of evaluating protein Quality. Proc. Nutr. Soc., 1958, 17 (1), 91.

[5] K. I. Carpenter et G. M. Ellinger. The estimation of " available lysin $"$ in proteins concentrates. Biochem. J., 1955, 61, XI.

[6] E. Kofranyi. Zur Bestimmung der biologischen Wert von Nahrungsproteinen. H. S's. Z. für Physiol. Chem., 1956, 305, 61.

[7] E. Kovacs. Vergleichende physikalische und chemische Untersichungen an Caseinen verschiedener Tierarten. Biochem. Z., 1940, 306, 74.

[8] R. Scober und Inge Prinz. Bestimmung des Lysingehalts in Milchproben nach der D N P Methode, in Abbängigkeit von ihrer Erhitzung. Milchwissenschaft, 1956, H. 12, 466.

[9] S. Sentheshanmuganathan and A. A. Hoover. Some aspects of destruction of Lysine under Conditions of acid and enzymic hydrolysis of Protein Materials Containing Carbohydrates. Biochem. J., 1958, 68,621 .

[10] M. X. Sullivan and W.C. Hess. A study of the various procedures for the estimation of Tryptophan. J. Biol. Chem., 1944, 155, 441. 